\title{
Descarga acústico-visual e temporalidades em cena: a fundação de uma tradição pela Banda Calypso
}

\author{
Phellipy Pereira Jácome \\ https://orcid.org/0000-0001-6939-7542 \\ Denise Figueiredo Barros do Prado" \\ https://orcid.org/0000-0002-0547-9896 \\ Rafael José Azevedo"I \\ https://orcid.org/0000-0002-5125-5957 \\ I - UFMG \\ Belo Horizonte (MG), Brasil \\ II - UFOP \\ Ouro Preto (MG), Brasil \\ III - Centro universitário UNA \\ Belo Horizonte (MG), Brasil
}

Resumo: O objetivo deste artigo é discutir, a partir do DVD comemorativo dos 15 anos da Banda Calypso, a proposição da fundação de uma tradição de música popular pelo grupo paraense. Para isso, em um primeiro momento, retomaremos o conceito de "descarga acústica" para entender a peculiaridade do discurso do grupo frente a tradições intelectuais já estabelecidas. Em seguida, abordaremos os mecanismos visuais e sonoros acionados pela Calypso no desdobramento de matrizes temporais específicas. Isso permitirá refletir como essas temporalidades são inscritas na textualidade do próprio DVD. Entendemos que o "brega", compreendido a partir de uma referência à matriz melodramática, consegue urdir tempos aparentemente desconexos e se torna um eixo condutor da narrativa.

Palavras-chave: música popular; Banda Calypso; brega; melodrama; tradição.

Abstract: Acoustic-visual release and temporalities on scene: the founding of a tradition by Banda Calypso: The purpose of this paper is to discuss the proposal to found a tradition of popular music made by Banda Calpyso in its 15-year commemorative DVD. Therefore, we seek to resignify the concept of "acoustic release " in order to understand the peculiarities of the discourse engendered by this group, especially in the questioning of established academic 
traditions. Then, we analyze the visual and sound mechanisms triggered by Calypso to configure specific temporalities. Our proposition is that the "brega", understood as a reference to a melodramatic matrix, can manage to unite seemingly disconnected times and becomes a guiding axis of the narrative.

Keywords: popular music; Calypso band; brega music; melodrama; tradition.

\section{Introdução}

"Sou Belém. Sou do Pará. Sou da Amazônia. Sou Brasil. Sou da galera... Alô, Belém do Pará. Isso é Calypso". Com furor da plateia, a cantora Joelma entra em cena, enfatizando suas marcas de pertencimento identitário ao citar trechos da canção "Balanço do Norte". Sua aparição foi precedida por uma vinheta instrumental construída sobre o ritmo do carimbó. A espacialidade cenográfica reforça esses vínculos pela exposição de elementos reconhecíveis: um enorme tablado foi montado na Cidade Velha de Belém, região portuária do Mercado Ver-o-Peso, tendo como cenário a Baía do Guajará. Nas laterais do palco, emoldurado pelas fachadas históricas, foram recriadas construções ribeirinhas de palafita e canoas que flutuam sobre uma piscina artificial. O palco é decorado por enormes vasos marajoaras, além de estampas no piso que remetem à iconografia amazônica. No centro da estrutura, destaca-se o monumento que faz com que a Praça Siqueira Campos seja popularmente conhecida como a "Praça do Relógio".

Apesar de logo na primeira imagem do show o velho relógio inglês marcar o início cronológico do espetáculo - por volta de 17 horas e 52 minutos -, e voltar a destacar-se ao final (seus ponteiros acusam aproximadamente 22 horas e 15 minutos), ele não está ali para medir intervalos lineares de tempo. Ao contrário, ele parece ser o índice das temporalidades concorrentes, divergentes e simultâneas, presentificadas nas quase duas horas que compõem o DVD comemorativo dos 15 anos da Banda Calypso. O DVD, gravado em 2014 e lançado em 2015, possui 29 faixas que trazem um panorama da carreira do grupo.

Há uma profusão de elementos utilizados no espetáculo que denotam, a princípio, um excesso - que diz de uma desordem e de um exagero formal e rítmico -, desafiando uma leitura linear. Além da composição cênica pontuada, mais de dez convidados mesclam interpretações de ritmos amazônicos trazidos como "tradicionais", passando pelo universo gospel e por fenômenos musicais mais "modernos". Apesar do excesso no espetáculo construído para a gravação do DVD, emerge a proposição de uma tradição que busca estabelecer a Calypso como o eixo transversal de uma história da música paraense, associado a matrizes da música pop. Por isso, neste artigo, observamos os mecanismos acionados para a construção dessa tradição, por meio da análise de estratégias de articulação de passado, presente e futuro, propostas no DVD. Para tanto, nosso percurso passará por alguns eixos teórico-metodológicos. 
Em um primeiro momento, abordaremos a questão da "suspensão da ordem do tempo", na medida em que, acreditamos, o conceito de "descarga acústica" proposto por Julio Ramos (2010) nos ajuda a entender o deslocamento e a fundação de tradições da nossa modernidade periférica. Isso permitirá atentarmos às especificidades das próprias tradições em que Calypso se inscreve, ressaltando, ao mesmo tempo, seu caráter histórico e o seu desejo de ser histórico. Afinal, essa tentativa de tradicionalização do "brega paraense" vem sendo disputada em produtos audiovisuais variados tal como observado por Azevedo (2017).

Em seguida, exploraremos como diversas temporalidades são inscritas na textualidade do DVD, a partir de uma análise dos elementos audioverbovisuais e das interações entre os artistas no palco e o público. Propomos que a música brega constituída pela Banda Calypso no DVD comemorativo, compreendido a partir de um excedente acústicovisual, consegue urdir tempos aparentemente desconexos e se transforma em um eixo que conduz à narrativa da fundação de uma tradição. Por meio da análise de elementos formais e discursivos da obra, problematizamos como esse gesto, tensionado por uma articulação multitemporal (entrecruzando movimentos temporais: antológico, tradicional e melodramático), torna-se fundante de uma "descarga acústico-visual".

\section{A "descarga acústico-visual" e a ordenação do tempo}

Sombrinhas de frevo se misturam a balões em formato de coração, bastões luminosos, "paus de selfie", bandeiras do Pará e cartazes com frases dirigidas a Joelma e a Chimbinha. Uma multidão se aglomera, diferentes corpos fruem e fluem em um movimento catártico durante todo o show apresentado no DVD. Mas nós, espectadores a posteriori do espetáculo gravado, também somos sacudidos pelas sonoridades e visualidades em cena. Nossos esquemas sensoriais são aparentemente impedidos de contemplar passivamente "o ritmo que conquistou o Brasil". Há como um desejo corporal que resiste à ação hierarquizante de conceitos aprendidos academicamente e que demarcam certos gostos musicais considerados "mais apropriados". Essa relação, longe de ser casual, é explicitada em muitas canções, como na "Na batidinha da Calypso":"quando começa a batidinha / ninguém fica mais parado / e a guitarrada do Chimbinha / vem fazendo mereado".

"Há momentos em que o estampido de uma música nova surpreende o filósofo" (RAMOS, 2010, p. 1, tradução nossa), "sacudindo seu corpo dos pés à cabeça" e sendo capaz de tirar o seu discurso do tempo. Nesses momentos, afirma Julio Ramos (2010), há uma descarga acústica que questiona as hierarquias do corpo formado a partir de uma história ilustrada do pensamento, bem como coloca em xeque uma perspectiva linear do tempo. Ramos (2010) retoma as anotações feitas por Walter Benjamin, em 1932, sobre seus passeios noturnos, pelas bordas de Marselha, para remarcar a surpresa pela qual foi apreendido quando ouviu o ritmo do jazz. Ao ser submetido à "descarga acústica" 
da música negra moderna, refletiu Benjamin (1932 apud RAMOS, 2010, p. 49, tradução nossa): "Esqueci com que motivação me deixei marcar seu ritmo com o pé. Isso vai contra minha educação e não ocorreu sem resistências interiores. Houve momentos em que a intensidade das impressões acústicas eliminava todas as demais".

Yi-Fu-Tuan (1983) apoia-se em preceitos semelhantes ao afirmar que

a música pode anular a consciência de direção no tempo e espaço de uma pessoa.

O Som rítmico que se sincroniza com o movimento do corpo anula o sentido da finalidade de uma ação de movimentar-se de um espaço e tempo históricos para alcançar um objetivo (TUAN, 1983, p. 143).

Por sua vez, Julio Ramos (2010) defende que essa força sensorial acústica é capaz de desestabilizar nossas percepções temporais e fraturar a divisão do trabalho que separa e estratifica corpo, mente e alma do sujeito. Esse "excedente acústico" seria responsável por exigir novos modos de compreensão da experiência sensória e do próprio tempo. Não por acaso, os cadernos de Marselha de Benjamin seriam tão diferentes de seus escritos sobre a capital francesa. Longe de ser um flâneur que contempla a profusão de produtos mercantis, o caminhante das periferias se atém às margens da cidade, local onde ocorre seu deslocamento sensorial. De maneira similar à zona portuária de Marselha para Benjamin, a região do Mercado Ver-o-Peso também funciona numa relação centro/ periferia. Afinal, é ali o porto em que muitas das produções amazônicas confluem: o rio, artesanatos, comidas, músicas, formas de ver, ouvir e saber o mundo. Ao colocarse nessa espacialidade, a Calypso se postula como resultante da mescla dessa cultura, territorializando e atualizando aquela região simbólica como um local no qual outros microcosmos entram em contato.

Nesse sentido, duas questões nos são aqui colocadas. Por um lado, concordamos com o potencial sonoro, capaz de rearranjar o esquema moderno, que fez do olho o seu principal órgão epistêmico. Vários autores (ABRIL, 2007; SCHAEFFER, 1993; SCHAFER, 2011), incluindo Benjamin, já abordaram a problemática relação de anestesia acústica a que somos formados e submetidos. Entretanto, e ressaltando as potencialidades sonoras do show registrado em DVD, propomos a ideia de uma "descarga acústico-visual", ampliando o conceito, para buscar apreender as relações audioverbovisuais instauradas pela articulação dos elementos em cena. Nesse ponto, é importante destacar que, dentre outros fatores, a experiência em um show in loco, como o da Banda Calypso é modalizada em função de uma pressão sonora e visual muito intensa e de um compartilhamento que não poderiam ser reproduzidos em espaços domiciliares. Ainda assim, uma experiência de outra ordem - também potente - emerge no contato com o DVD analisado: sua dimensão visual, bem como a trama formada a partir de múltiplos elementos musicais, ordenam um fluxo capaz de configurar uma experiência de "descarga acústico-visual", ao colocar

1 A partir de sugestão da pesquisadora Juliana Gutmann, a quem agradecemos a contribuição. 
em relação iconografias e heranças trazidas pela banda no DVD e, ao mesmo tempo, desestabilizar a hierarquia formal de nossos corpos - a partir de modulações, mixagens e de relações verbovisuais explicadas adiante -, tirando-nos da ordem linear do tempo, por um excesso que não pode ser contemplado passivamente.

Por outro lado, também nos interessa abordar o que os sujeitos inscritos em cena e provocadores dessa descarga têm a dizer sobre a hierarquização que propõem. É nesse momento que um conjunto de tradições musicais não muito consolidadas pela crítica e pela academia, tal como o "brega" (ARAÚJO, 2013; AZEVEDO, 2019; BARROS, 2011; COSTA, 2013;), faz-nos questionar os pressupostos analíticos sedimentados nas discussões voltadas à música popular. Além da dificuldade de estabelecer um encadeamento narrativo linear no DVD, é preciso repensar como uma "invenção da tradição" é estrategicamente proposta/acionada pelos próprios sujeitos. Por uma articulação de práticas, rituais ou simbólicas, determinados valores são acionados para "estabelecer uma continuidade com o passado histórico apropriado" (HOBSBAWN, 2012, p. 8).

Tais ideias são formuladas por Hobsbawm (2012) diante da observação da invenção de tradições modernas em contextos europeus, quando certas ritualidades substituem práticas sedimentadas no passado. A proposição de uma continuidade e a remissão a um tempo fundador e impreciso tornam-se estratégicas para que se fortaleça a ideia de que "sempre foi assim" e "assim será". Não sugerimos que as operações propostas pela Banda Calypso no DVD estejam claramente curvadas a tais premissas, mas nos parece potente pensar como essa entidade artística opera a fundação de uma tradição, a partir da articulação de referências temporais muito diversas que parecem circular "desde sempre", em seu discurso, a partir de Belém. De toda maneira, o excedente acústico-visual e temporal característico desse DVD, em específico, impõe questionamentos também à história já preestabelecida da música popular, posta em disputa pela Calypso.

Se por um lado essa multiplicidade referencial acaba engendrando um aspecto pop e cosmopolita (PRYSTHON, 2004), por outro, notamos que o DVD destaca uma suposta cultura amazonense e o faz, em determinados momentos, tomando como referência uma audiência estrangeira. O interlocutor de "Dançando calypso", por exemplo, é instado a aprender um ritmo desconhecido e a visitar o Pará para encontrar "isso e muito mais". Em outros momentos, esse interlocutor externo, ainda que não explicitado, faz-se presente na regulação dos corpos em cena. Em "Chama guerreira" - canção que se inscreve ritmicamente como uma "toada de boi" -, o figurino de David Assayag (roupa verde, com plumas) e Edilson Santana (roupa azul e com estampa animal print e chapéu com plumas) faz referência a um universo simbólico amazônico.

Tal como em um DVD de música pop convencional, a performance de Joelma, por exemplo, vai se alterando repetidas vezes ao longo dessa narrativa. Ora a cantora está claramente atuando, ora deixa escapar relações de afeto mais íntimas com 
o seu então companheiro Chimbinha. Ora está falando de temas universalizantes, como amor, traição, paixões; ora demonstra uma necessidade de reafirmar como esses temas são formulados a partir de uma identidade amazônica/paraense específica. Há troca incessante de figurinos, que, a princípio, não teria relação óbvia com a musicalidade ou com a tradição proposta, embora seja algo que dialogue com o universo dos grandes concertos de música pop. De fato, o mesmo vestido vermelho de gala pôde ser utilizado em canções românticas, como em "Fórmula mágica", e em um momento religioso, com a presença da pastora Ludmila Ferber, na música "Unção sem limites". A guitarra, elevada a ícone em vários momentos do show, também é utilizada na passagem religiosa. Há justaposição de elementos de matrizes distintas: Joelma pode usar roupas inspiradas em temas amazônicos, mas também o faz a partir de imagens que nos convocam de Xuxa a Beyoncé.

Mais do que observar aí uma mescla das tradições, evidenciamos que a trama de temporalidades se torna constitutiva da descarga acústico-visual engendrada pelo DVD da Calypso: ao urdir diferentes temporalidades, o "brega" confere a sensação de excesso que conduz a uma ruptura com a própria noção de linearidade do tempo. Se em um primeiro contato com o DVD comemorativo dos 15 anos da Calypso, a sensação é de um excesso desarticulado, em uma observação mais atenta, percebemos a música brega como um fio narrativo que organiza as temporalidades ali entremeadas e dá sentido ao conjunto da produção.

Ao estruturar-se enquanto forma cultural, "o brega" - não somente como gênero musical, mas como uma prática articuladora de saberes e sensibilidades que atravessam o popular (FACINA, 2011; SOARES, 2018) - faz emergir um novo ordenamento. Essa organização entrecruza as múltiplas temporalidades investidas na ação e estabelece uma cadência entre elas, de modo que o momento da performance no palco refere-se tanto a um antecedente histórico do grupo quanto a uma historicidade das práticas culturais paraenses e cosmopolitas, convocadas para compor a performance do show. Assim, percebemos um esforço de encarnar essas múltiplas temporalidades e inscrever nelas corpos e saberes. Diante disso, perguntamo-nos como encarar essa tradição "inventada" diante do desejo de ser paraense/amazônico, ao mesmo tempo que histórico/moderno? Não deixa de ser curiosa a afirmação repetida de que "Isso é Calypsoooo!". O "isso" claramente é algo em disputa e em afirmação. Quais elementos essa "descarga acústico-visual" promovida no DVD engendra?

\section{Tradição e contradição na Calypso}

A Banda Calypso se formou no final dos anos 1990, quando Joelma Mendes mudou-se de Almeirim, no Baixo Amazonas, para Belém, em busca do sonho de ser cantora. Transitando pela capital paraense, entrou na cena "brega pop" (também chamado de 
"calypso"), que estava em grande efervescência na segunda metade dos anos 1990 (COSTA, 2009). Nesta época, ela conheceu Cledivan Almeida Farias, o Chimbinha. O guitarrista e produtor, nascido em Oeiras do Pará, atuava na capital há alguns anos, tendo participado de centenas de gravações como músico de apoio ou mesmo arranjador/produtor, além de ter lançado um álbum de guitarrada em 1998, o "Guitarras que cantam" (VIANNA; BALDAN, 2000). O DVD de 15 anos da Calypso foi o último da banda, já que, no mesmo ano do seu lançamento, Chimbinha e Joelma romperam. Há, nele, uma tentativa de colocar o grupo como uma espécie de dobradiça na história da música popular paraense, frisando "um antes e um depois", que teria a Calypso como ponto médio.

No disco, percebemos três formas pelas quais um excesso acústico-visual é trabalhado nessa textualidade, desdobrando-se temporalmente na proposição de uma tradição. A esses movimentos do tempo denominamos antológico, tradicional e melodramático: o primeiro se articula pela seleção de canções performadas e artistas convidados; o segundo se instaura na convocação de heranças/passados musicais, de modo a afirmar a relevância cultural e histórica da Calypso; o último, por sua vez, diz respeito às dinâmicas temporais "internas" da narrativa construída ao longo do tempo de execução do DVD comemorativo.

\section{Tempos do excesso: 0 antológico, o tradicional e o melodramático}

O tempo antológico se evidencia nas tentativas de elaborar e remontar a um passado fundador para a banda e constituir uma trajetória de sucesso a partir das produções musicais e parcerias desenvolvidas. A Calypso, diante e a partir das origens paraenses-amazônicas - que abordaremos no próximo tópico -, constitui um caminho muito próprio e que, no que se dá a ver e ouvir no DVD, articula-se no diálogo com distintos domínios de música popular local e global.

Indica-se que a banda, mesmo após 15 anos de trabalho, segue inovando e apresentando novas canções, que se inscrevem como articuladoras entre passado e presente. A abertura do show com "Vamos ficar de bem", que era o mais recente single, é um bom exemplo: a canção tem uma constituição musical ("brega pop"/"brega calypso") e temática amorosa, que dialoga com o que há de mais representativo na carreira do grupo. É apresentada em um bloco que percorre suas "origens" com as performances de "Passe de mágica" (do Volume 8 de 2007, álbum indicado ao Grammy Latino) e "Dançando calypso", primeiro grande sucesso do grupo, presente no disco de estreia da banda, de 1999. Na sequência proposta no DVD, a banda começa, logo depois, um novo bloco de "novidades", sendo a primeira delas a música "Vibrações" que destoa ritmicamente das anteriores, mas dialoga com outras referências da música paraense. A linha de guitarra do refrão, as progressões harmônicas e o ritmo fazem referência ao arranjo de "Onde andará você" lançada na voz de Alípio Martins, um dos mais conhecidos artistas relacionados ao carimbó, à lambada e ao "brega paraense" dos anos 1980. 
Nesse sentido, a banda se antologiza, de modo a reforçar não apenas suas marcas identitárias amazônicas e paraenses, mas também como estratégia para se apresentar como parte de uma rede de relações que acabam transcendendo as marcas locais. Há algumas ocorrências nesse sentido: a banda rememora, por exemplo, sua aproximação com o forró eletrônico, ao trazer os vocalistas da Banda Calcinha Preta, em "Como eu te amei", também do disco mais recente; em outro momento, Joelma convida o cantor Daniel, em "Minha vida não é vida sem você", o que demonstra uma aproximação ao fenômeno sertanejo "anos 90" - algo já sinalizado por Hermano Vianna (2007).

Como adensamento do antológico, o tempo tradicional se refere à tentativa recorrente de ressaltar a produção cultural da banda com um repertório paraense/amazônico: são estabelecidas conexões tanto com a cidade e sua espacialidade, quanto com aquilo que se consideraria tipicamente paraense. É neste domínio que aparecem objetos cenográficos para compor o palco, como remissão à paisagem amazônica. Usam-se, nos figurinos, cocares e penas como alusão ao indígena. Adotam-se ainda, entre a cantora e as bailarinas, saias rodadas e floridas, colares de flores plásticas, dialogando com um estilo "carimbó" (COSTA, 2013), gerando uma mescla com o que se supõe afro-indígena, fazendo emergir uma série de misturas com representações midiáticas da região amazônica. Para compor esse vínculo com o tradicional, um conjunto de traços musicais são propostos para relacionar a trajetória da Calypso a um panorama cultural paraense. Há blocos que abrem claramente esse diálogo, a partir de canções como a lambada "Gritar de amor" (do "Calypso acústico" de 2008), que nos lembra canções famosas dos grupos Gipsy Kings e Banda Warilou (que atua em Belém desde os anos 1980). Em seguida, performa-se uma das lambadas de maior sucesso da banda, "Esperando por você".

Outra passagem que articula a temporalidade tradicional é marcada por uma diferenciação no figurino de Joelma, com um cocar na cabeça; Chimbinha, por sua vez, toca um charango, instrumento de origem andina. A cantora anuncia um grupo de dança, Wancó, e os cantores David Assayag e Edilson Santana, ligados ao universo do Festival Folclórico de Parintins e das "toadas de boi". A canção "Chama guerreira" é permeada de signos amazônicos, ao mesmo tempo em que são justapostos na cena elementos religiosos mais globais (com referências a Buda e a Krishina), somados a um discurso de totalidade nacionalista: "o que mais quero nessa vida / é ver meu povo feliz cantar / ver minha nação unida".

O conjunto, porém, que remete de maneira mais efetiva a essa tradição é anunciado por Joelma depois de 1 hora e 20 minutos do DVD: "E agora eu vou contar uma história pra vocês, musicalmente falando, de um ritmo que deu o nome a esta banda". Nesse momento, é proposta uma pequena revisão do "brega paraense", ainda que essa expressão seja dissimulada. Especula-se que o uso do termo "calypso" foi uma estratégia de distinção nos anos 1990 (VIANNA; BALDAN, 2000) e revela não só o desconforto e o preconceito que o termo "brega" engendra historicamente (ARAÚJO, 2013), como também aponta para 
referências caribenhas nas sonoridades daquela versão amazônica do ritmo romântico (LAMEN, 2013).

A primeira canção do bloco é "Por não ter o seu olhar", gravada por Teddy Max, em 1986, representando uma primeira geração do "brega paraense". Na introdução da faixa seguinte, a cantora anuncia: "e ele ["o brega"] foi crescendo, e se transformou nesse ritmo agora ["o calypso"], ó... mais gostoso, mais acelerado". A banda, então, toca quatro canções lançadas já na segunda metade dos anos 1990, trazendo ao palco seus intérpretes originais: "Agora eu não sei", com Alberto Moreno; "Não me deixe só", com Edilson Morenno; "A cura", com Marcelo Wall - introduzida por Joelma como "o momento da sofrência". Encerrando a presença de uma "segunda geração do brega paraense", a cantora anuncia: "agora chega ele, mais dançante do que nunca", e começa a performance de "Gererê", com participação de Nelsinho Rodrigues. Por fim, a banda faz uma versão de "Vem meu amor (Xa na na)", com Viviane Batidão, introduzida assim por Joelma: "e veio o tecno, ele cresceu, ele cresceu...". Todos os convidados permaneceram no palco até a performance dessa canção acabar. Ao todo, esse trecho do show, que pretende contar a fundação do "calypso", possui mais de 20 minutos.

Há um esforço em associar o grupo às tradições culturais paraenses, como forma de estabelecer um momento fundador, indicar as raízes e trazer à tona o caráter comemorativo dos 15 anos. Não se trata somente de celebrar a Calypso, mas também a emergência e a continuidade da música paraense, em especial “ do brega", no cenário nacional. Esse esforço de alinhavar tempos e sugerir dinâmicas de sucessão entre eles mostra que o objetivo do grupo passa por construir um passado e demarcar uma inserção em um panorama cultural mais amplo: nesse esforço, é preciso vincular diretamente a história da banda às referências culturais paraenses, bem como atestar a continuidade dessa presença e desse diálogo, sem abrir mão de uma narrativa que pincele sua transcendência para além do local.

Destaca-se também a entrada de novos parceiros, que cumprem uma dupla função no show: atualizam o vínculo da Banda Calypso com a produção paraense contemporânea (como é caso de Lia Sophia, que canta "Ai, menina", música que remete ao carimbó e se tornou um sucesso nacional pela telenovela da Rede Globo, "Amor, eterno amor", de 2012) e mostram o diálogo entre outros gêneros musicais, como é o caso da presença do cantor sertanejo, Daniel.

Essa associação a artistas que não possuem vinculação paraense pode parecer contraditória, já que, de alguma maneira, esgarça suas origens ao tensionar as fronteiras territoriais de sua prática cultural. No entanto, esse exercício demarcado pela Calypso no DVD, ao apontar a continuidade/resistência das tradições locais do Pará, não lhes isola no cenário nacional; diferente disso, permite sua inserção no panorama cultural mais amplo e viabiliza uma circulação robusta de suas produções. A constituição desse regime temporal mesclado objetiva então trazer um passado e uma 
história de fundação ao grupo, bem como inscrevê-lo como pertencente ao cenário cultural brasileiro contemporâneo.

Já o tempo melodramático refere-se à possibilidade de um tempo da própria vivência do espectador, na fruição desse produto midiático e na relação proposta pela atuação dos artistas diante das câmaras. Esta denominação se deve ao entendimento de que é neste momento de contato entre público e artista, exibidos no DVD, que são instaurados laços afetivos que acenam para adesões morais, emoções e afetividade, que fazem apelo ao melodrama como matriz cultural articuladora das mesclas constitutivas de uma identidade cultural. Esse eixo torna ainda mais saliente o esforço de constituição e restauração do laço do grupo com o Pará, por meio do qual a banda tenta demarcar a sua presença. Essa proposição de relação pode ser percebida no DVD em três elementos estruturadores: o extravasamento das emoções; a ludicidade e o engajamento; e o desentranhamento e a mescla do real e do ficcional.

O extravasamento das emoções pode ser notado na performance estetizada das paixões e dos sentimentos, destacando o transbordamento emocional diante do sofrimento amoroso. No DVD, a expressividade das emoções e o engajamento se tornam uma marca bastante forte; as músicas são, em grande medida, encenadas pelo corpo de bailarinos e pela cantora. Essa encenação não é aleatória: ela dá a sensação de que no show partilhamos as nossas dores: procura-se identificação e passibilidade na relação com as audiências, como forma de mostrar que se compartilha (e se compreende) o sofrimento e a superação. Notamos o exagero na narração e expressão das emoções, por exemplo, ao tentar descrever a intensidade com que se ama, em "Como eu te amei", com o grupo Calcinha Preta, no qual se afirma que "te amei por todos os sete mares", cantado a "plenos pulmões".

Quanto à ludicidade e ao engajamento, observamos como o corpo se converte num recurso capaz de criar um vínculo entre a banda e o público. Há canções que têm, inclusive, caráter pedagógico, que convoca à dança como um jogo em que se aprende e se engaja, pois "ninguém fica mais parado" ("Na batidinha da Calypso"). Nesses momentos, o vínculo se fortalece, uma vez que a própria letra demanda um tipo de associação e gestualidade, voltada para a presença da audiência.

Ainda neste traço constitutivo do tempo performático, destacamos a força da linguagem popular, que procura gerar identificação e comunicar um modelo de interação que escapa às formas cultas ou convencionais. São utilizadas expressões informais e frases clichês para falar das relações amorosas: "estou a ponto de enlouquecer / pra você voltar estou rezando / você é o homem que escolhi", "Esperando por você"; "alegria sem você não existe", "Fórmula mágica"; "vamos ficar de bem", "Vamos ficar de bem".

Observamos que o público é uma referência para a fala e a gestualidade da artista no palco, mesmo que, visualmente no DVD, ele ganhe pouco espaço e corporeidade. Isso dá a sensação, inclusive, de que a produção está mais centrada na banda e num público 
externo ao show, o telespectador do DVD, do que no público presente no dia do registro. Isso fica evidente porque, embora haja um discurso de proximidade da artista com a audiência, há poucas imagens das pessoas presentes na plateia; as falas de interação entre artista e convidados com o público foram, em geral, suprimidas na edição final; e boa parte no palco traz enquadramentos em que a cantora encara a câmera, estabelecendo o eixo olhos-nos-olhos (VERÓN, 1983), consagrado em produções audiovisuais ligadas à música popular midiática.

Outro traço do tempo performático é o desentranhamento e a mescla do real e do ficcional. Eles podem ser observados nas situações em que se cruzam elementos da vida fora dos palcos com o jogo, com a brincadeira ou mesmo com a representação das emoções desenvolvidas no show. Percebemos como o fato de Joelma e Chimbinha serem um casal afeta o desenrolar das interações no palco. Em "Fórmula mágica", dá-se ênfase à presença de Joelma e Chimbinha no palco, à troca de olhares entre eles. Já nas músicas de ruptura e fim de relacionamento, Joelma fica próxima do corpo de dança, olha para o público presente e se distancia do guitarrista.

Isso se torna mais evidente em "Objeto de desejo", em que se narra a história de uma mulher que descobre um envolvimento amoroso com um homem casado. Um pequeno teatro é montado: uma das dançarinas é a esposa traída e Joelma, a amante enganada. Na cena, Joelma finge estapear o amante (um dos dançarinos), empurra-o, afastando-o com a mão. Nesta canção, Chimbinha fica ao fundo e não aparece no conjunto da cena. Ao fim da canção, o amante retorna à esposa, sendo arrastado pelas orelhas para fora do palco. Enquanto eles saem de cena, Joelma fala, taxativa ao público: "cabra safado é assim".

Essas encenações das músicas românticas e de traição marcam uma relação implícita entre a teatralidade do palco e sua dimensão ficcional com o mundo real, o referente externo ao show, no qual Chimbinha e Joelma eram casados. Assim, nas relações de afeto e amor "verdadeiro", Chimbinha se torna o par de Joelma; no escracho e no discurso moralizante, apela-se para o ficcional. Essa "gestualidade brega" tem como impacto um entrecruzamento entre o palco e a vida social, mesclando essas duas ambiências em prol do reforço das relações amorosas ali em curso. Mais do que isso, "o brega" parece afirmarse como tradição ao combinar essas temporalidades antológica e performática, fazendo concordar os elementos múltiplos que forjam a "descarga acústico-visual".

\section{Algumas considerações sobre "o brega" e a urdidura do tempo}

O DVD comemorativo dos 15 anos da Banda Calypso expõe estratos temporais contraditórios, mas também complementares. Há tentativa de fundar uma tradição nos moldes daquilo que Hobsbawm (2012) entende como uma "invenção". Isto é, uma explicitação ritualística que visa a inculcar certos valores e normas, buscando estabelecer uma continuidade em relação a um passado histórico elevado e vivenciado 
como comunitário. A Calypso tenta se estabelecer como o eixo central de uma tradição popular paraense, incorporando, no presente, um passado comum e sedimentado, e um futuro inovador e perpetuador. Nesses gestos, a própria "performance brega" expõe outras bases temporais, que agregam à camada nativista um atravessamento latino-americano, caribenho e cosmopolita/pop, revelando-se como uma "descarga acústico-visual".

Percebemos, desse modo, uma espécie de "urdidura brega", na tutela do tempo ensejada por Calypso: várias tradições populares são retomadas em uma trama complexa, que se assume como um poderoso aglutinador em torno de identidades justapostas, na qual há clara simultaneidade assincrônica. Essas contradições propiciadas pela audioverbovisualidade da banda, desse modo, carregam aproximações e diferenças àquilo que Julio Ramos (2010) define como "descarga acústica". Se ali uma identidade europeia/ ocidental é fraturada pelo contato arrebatador com zonas de fronteira cultural, o sujeito latino-americano-caribenho já constrói sua relação identidade/alteridade numa espécie de diferença que já une margem/centro. Isso, a nosso ver, explica o ensejo nativista de Calypso associado a outros desejos universalizantes. Esse sujeito já parece ser ele mesmo, uma descarga problemática à ordem linear do tempo imposto por visadas demasiado eurocêntricas, que incluem aí certamente muitos olhares acadêmicos. Além disso, os recursos visuais na proposição de corpos e objetos no cenário são também fundamentais na especulação que propomos em torno da "descarga": há um excedente visual que nos interpela, motivo pelo qual a modulação do conceito para uma "descarga acústico-visual", aliada a uma "estética brega", parece-nos produtiva.

"O brega" e a ideia de "descarga acústico-visual" não se apresentam como chaves de leitura estáveis nem previsíveis. Diversamente disso, permitem compreender a cotidianidade e a proximidade corporal e sensória no entendimento das emoções investidas na vivência cultural. Urdindo-se pelo "brega", convergem formas de lidar com os corpos, com as tradições e com os tempos; à luz da "descarga acústico-visual", articulam-se reflexões sobre a construção de uma tradição, enquanto continuidade possível, mesmo que, a partir de temporalidades múltiplas tal como inscritas no DVD. A análise revela assim, que ao abolir lógicas dualistas, inclusive negando fronteiras entre o moderno e o tradicional, entre o popular e o massivo, a Banda Calypso adota como traço constitutivo: o sincretismo entre o cotidiano e a performance cultural.

Com isso, "o brega" viabiliza uma leitura complexa que, por sua cotidianidade, é afetada e remodelada pelas dinâmicas da vida social: ao mesmo tempo que faz apelo aos traços do melodrama, incorpora elementos associados à vivência dessa prática cultural singular. A narrativa emergente no DVD é tensionada pelas mudanças contextuais, pela vida cotidiana e o seu fio narrativo nasce do arranjo das narrações e dos reconhecimentos travados no decurso das ações dirigidas para o ordenamento dos sentidos.

O DVD "Banda Calypso - 15 anos" (2015) é então marcado pelo trânsito entre o cotidiano e a performance cultural. Ali, misturam-se tempos, valores e ambiguidades, 
ainda que a trama desta produção se anuncie como uma antologia da banda, realçando a todo momento suas tradições e "origens". Múltiplas narrativas se desenham, mesclando-se e contradizendo-se, como uma "descarga acústico-visual", fazendo com que "o brega" emirja como rico articulador na análise de objetos culturais fundados às margens de temporalidades lineares e aparentemente mais coesas.

Phellipy Pereira Jácome é professor do Departamento de Comunicação Social da Universidade Federal de Minas Gerais e Pesquisador Permanente do Programa de Pósgraduação em Comunicação (PPGCOM/UFMG) na linha de Textualidades Midiáticas. É doutor em Comunicação Social pela UFMG, com estágio doutoral na University of Illinois at Urbana-Champaign, como bolsista CapesPDSE. É pesquisador do Núcleo de Estudos Tramas Comunicacionais: narrativa e experiência.

phellipyjacome@gmail.com

Denise Figueiredo Barros do Prado é professora do curso de Jornalismo e do Programa de Pós-Graduação em Comunicação da Universidade Federal de Ouro Preto, na linha Práticas Comunicacionais e Tempo Social. É doutora em Comunicação, pelo Programa de Pós-Graduação em Comunicação da UFMG, com estágio doutoral na École des Hautes Études en Sciences Sociales, com bolsa CapesPDEE. É co-coordenadora do Grupo de Pesquisa em Mídia e Interações Sociais - Giro.

denisefbp@gmail.com

Rafael José Azevedo é professor do curso de Cinema e Audiovisual, no Centro Universitário Una, em Belo Horizonte e doutorando na linha de pesquisa Textualidades Midiáticas, do Programa de Pós-Graduação em Comunicação Social da Universidade Federal de Minas Gerais (PPGCOM/UFMG), com estágio doutoral no Departamento de Periodismo III, da Universidad Complutense de Madrid. Atua na área de produção fonográfica como compositor, arranjador, produtor e técnico de áudio.

rafaeljoseazevedo@gmail.com 


\section{Referências}

ABRIL, G. Análisis crítico de textos visuales. Madrid: Síntesis, 2007.

ARAÚJO, P. C. Eu não sou cachorro não. Rio de Janeiro: Editora Record, 2013.

AZEVEDO, R. J. Do brega paraense ao tecnobrega: história e tradição na websérie Sampleados. In: Galáxia, São Paulo, n. 35, 2017.

Derivas do brega paraense: escutas em tempos e lugares múltiplos. 2019. Tese (Doutorado em Comunicação)- Universidade Federal de Minas Gerais, Belo Horizonte, 2019.

BARROS, L. G. Tecnobrega: a legitimação de um estilo musical estigmatizado no contexto do novo paradigma da crítica musical. 2011. Tese (Doutorado em Comunicação) - Universidade Federal de Pernambuco, Recife, 2011.

COSTA, A. M. D. Festa na cidade: o circuito bregueiro de Belém do Pará. 2. ed. Belém: Eduepa, 2009.

COSTA, T. L. "Música de subúrbio": cultura popular e música popular na hipermargem de Belém do Pará. 2013. Tese (Doutorado em História)- Universidade Federal Fluminense, Niterói, 2013.

FACINA, A. (Org). Vou fazer você gostar de mim: debates sobre a música brega. Rio de Janeiro: Multifoco, 2011

HOBSBAWM, E. J. E. A Invenção das tradições. 3. ed. Rio de Janeiro: Paz e Terra, 2012.

MARTÍN-BARBERO, J. Dos meios às mediações: Comunicação, cultura e hegemonia. Rio de Janeiro: Editora UFRJ, 2009.

LAMEN, D. Claiming caribbeanness in the Brazilian Amazon: lambada, critical cosmopolitanism, and the creation of an alternative Amazon. Latin American Music Review / Revista de Música Latinoamericana, Austin, v. 34, n. 2, p. 131-161, 2013.

PRYSTHON, A. Diferença, pop e transformações cosmopolitas no Recife a partir do Movimento Mangue. In: Revista Fronteiras: estudos midiáticos. v. 1, p. 33-46, janeiro/junho, 2004.

RAMA, A. Transculturadón narrativa en América Latina. 2. ed. Buenos Aires: Ediciones El Andariego, 2008.

RAMOS, J. Descarga acústica. Papel Máquina: Revista de Cultura II, n. 4, p. 49-80, 2010.

SCHAEFFER, P. Tratado dos objetos musicais. Brasília: Editora Universidade de Brasília, 1993.

SOARES, T. "Ninguém é perfeito e a vida é assim": a música brega em Pernambuco. Recife: Outros Críticos, 2017.

SCHAFER, R. M. O ouvido pensante. 2. ed. atual. São Paulo: Ed. Unesp, 2011.

TUAN, Yi-Fu. Espaço e lugar: a perspectiva da experiência. São Paulo: Difel, 1983.

VERÓN, E. Está ahí, lo veo, me habla. Revista Comunicativa, n. 38, 1983. (Enonciation et cinéma, Seuil, París). Tradução de María Rosa del Coto.

VIANNA, H. Isso é Calypso - Ou A Lua Não Me Traiu. 2007. Disponível em: <http://www.overmundo. com.br/overblog/isso-e-calypso-ou-a-lua-nao- me-traiu>. Acesso em: 27 jul. 2014.

; BALDAN, E. Música do Brasil. São Paulo: Editora Abril, 2000.

Videografia

BANDA CALYPSO. Banda Calypso - 15 Anos. São Paulo: Radar Records, 2015. 1 DVD (119 min). 